\title{
Study on Human Capital Loss and Restoration for Climate Induced Migrants*
}

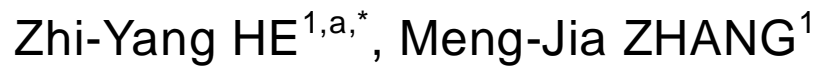 \\ ${ }^{1}$ Hohai University, No.1 Xikang Road, Nanjing, P.R.China, 210098 \\ ayangzhi8436@163.com \\ ${ }^{*}$ Corresponding author
}

Keywords: climate change, climate induced migrants, human capital, livelihood restoration

\begin{abstract}
With the scale of climate-induced migration gradually increasing, livelihood problems for climate migrants are becoming increasingly severe, which is mainly the consequence of human capital loss during the process of climate-induced migration. Human capital impacts job opportunities, migration destination, cross-generation development and other aspects of climate migrants' life through intellect and skills, physical and psychological health, hence significantly affects the sustainability of their livelihood. In order to restore the sustainable livelihood of climate migrants, efforts, including improved school education, enhanced vocational training, learning by working, enlarged investment in healthcare, perfected social security system, etc., have to be taken into consideration to restore human capital for climate migrants.
\end{abstract}

\section{Introduction}

With global climate change getting increasingly intense, migration induced by extreme climate conditions and disastrous climate events is showing a growing tendency, and it has gradually caused widespread public concern. Especially in fragile ecological area, climate disasters -such as floods, hurricanes, drought, tsunami, sea level rise and so on, usually induce environmental degradation, loss of property, income decline and population loss, and force some people have to leave their homeland, difficult to start a difficult life in a new area. In this process, some of the migrants even become climate refugees. An assessment report issued in 1990 by the United Nations Intergovernmental Panel on Climate Change, pointed out that 'the most severely consequence induced by climate change is likely to produce millions of migrants' (IPCC, 1990). In 2007, Christian Aid predicted that by 2050 nearly one billion people will be permanent relocated, of which a quarter is due to climate reasons such as drought, floods and hurricanes et al.

Climate migrants refer to those who, either compelled or of their own free will, have left their hometown temporarily or permanently for migration destination in domestic or abroad, under the adverse impacts on their life or living conditions due to sudden or gradual climatic degeneration as well as current climate policies or projects. In recent years, the migrant population caused by climate change has aroused mounting public attention. By far, correlation between climate change and population migration has displayed a tendency as: climate change $\rightarrow$ ecological imbalance $\rightarrow$ environmental degeneration $\rightarrow$ climate policy disclosed $\rightarrow$ climate project constructed $\rightarrow$ climate migration $\rightarrow$ local socio-economical system reconstruction (Chen Shaojun \& Cao Zhijie, 2012). This involuntary resettlement process usually makes them fell into poverty. Mathur (1995) argued that the community decay, family separation, livelihoods destroy raised by involuntary resettlement cannot be measured by money. Cernea (1998) also found that the involuntary resettlement could lead to the loss of land, loss of their jobs, loss of their homes, relocation to the edge area, lack of food, declining of health, loss of common property, and disrupt of social network and other risks for affected households and persons, thereby increasing the risk of poverty for relocated people. The conduction mechanism of climate change affecting population migration is shown in Figure 1.

\footnotetext{
${ }^{*}$ *This paper belongs to findings of Project supported by the National Social Science Fund Study on the Resettlement Policy of Population Migration under the Influence of Extreme Climate (No. 11CRK002) and Study on Correlation between and Policy of Climate Change and Population Migration (10BRK001).
} 
Human capital is a form of capital from human themselves, a consequence of human investment such as formally organized education and on-the-job training, plus other expenditures like opportunity cost; it is the overall stock of production techniques, laboring and management skills, and health (Theodore W.Schultz,1971).

The human capital theory considers that human capital is the most important of all resources, and human capital outweighs material capital in economic growth. Human capital plays a significant role in the restoration of climate migrants' livelihood. In the process of migration, human capital usually suffers losses for a shift of living environment. The loss and lack of human capital for climate migrants, is the significant origin of their poverty. So it is an important way to get rid of poverty by enhancing the human capital investment for climate migration. Schultz (1961) considers that poverty in developing countries is the result of lack of human capital investment opportunities, and the decisive factor to improve the welfare of poor is the improvement of their human capital quality. Amartya Sen (2000) believes better education and health care can not only improve the quality of life, but also increase income and the ability to get rid of poverty. Therefore, through a variety of ways to enhance human capital of poor become an internationally recognized important Anti-Poverty Strategies. Regard to climate migrants who belongs the social vulnerable groups, the reconstruction of human capital is more important.

From a perspective of human capital theory, this paper studies the mechanism of influence of human capital on the restoration of climate migrants' livelihood, analyzes human capital losses during climate migration as well as the ensuing livelihood problems, and then explains how human capital of migrants might be reconfigured so as to facilitate the restoration and development of climate migrants' livelihood after relocation.

\section{Human capital loss and livelihood problems of climate migrants}

Human capital loss of climate migrants. Production and living techniques as well as experiences that climate migrants developed through laboring in their original residential area enable them to make a living in local environment. However, as a consequence of climate deterioration in their original residential area, they have to migrate to new places, in which life and production might not be the same as former, or even might be totally different. In this regard, there would be human capital losses, resulting in a lack of living techniques, income decrease, and inferior quality of life in a certain time, which might be even life-threatening if it lasts for too long a time. Besides, migrants' health during the migration might be fragile to strange environment in which they might be endangered or get sick because of accidents or inappropriate diet; since they have not yet to adapt to the new environment, plus incomplete social supporting network, they might be prone to psychological problems such as anxiety and depression for stress overload.

In a word, climate migrants suffer losses of important human capital such as laboring techniques, production and living experiences as well as physical and psychological well-being, which is one of the most important internal causes for livelihood problems of climate migrants, but is also the cause that is easy to be overlooked in the process of resettlement.

Livelihood problems of climate migrants. With climate change getting increasingly intense, climate calamities are, to a greater extent, posing an adverse impact on local socio-economic system, and climate migrants in their migration process would be confronted with various livelihood problems, as shown below.

Loss of land. Climate change results in environmental variation and climate calamities, which would pose great threat as well as challenges to the life and production of people who live in a certain area, and then they would have to leave their home town for a better living and development, thus bearing the loss of their land. For migrants, especially those from rural areas, land is essential to their life in that it is not only the main source of their income, but also an important guarantee of their daily life, the last shelter and refuge for farmers. The loss of land, to the migrants, does not only mean a decrease of income, but also a changed way of living and working. For migrants who have comparatively less human capital, it would be difficult to change their occupations, which further exacerbates their livelihood problems. 
Loss of work. Skillful production techniques of climate migrants are developed through long-term working in their original residential area, which might be incompatible with production needs in places they now live in as a result of differences in production methods. In their original residential area, their time-tested skills and techniques could suit well to local environment and productivity levels, and as most of them all have some expertise, it is not impossible at all for them to find a job and live an abundant life out of it. However, after migration, their original skills and techniques might be inadequate for the new environmental and technological requirements. When skills of climate migrants are left useless in their new places of residence, unemployment would ensue, during which the climate migrants would find them unable to keep up their former living standards.

Damage of houses. If it has not been formulated in the migrant resettlement policy to improve housing conditions, or if compensation fees for demolished houses are paid at the market price instead of replacement price, then some of the climate migrants might have to lose their houses temporarily. Labor input in house reconstruction might considerably prolong the construction period, and if the resettlement house construction lags behind the migration process, or if compensation funds are of too small number or come too late so that there is insufficient money for rebuilding, then climate migrants would have to live in temporary shanties, and there would be chances that the climate migrants could be left homeless for an indefinitely long period of time.

Food shortage. Without land, climate migrants would have to buy almost all the food they need after migration since there is now no land that could produce crops as part of food source. And thus for those who have no source of external income, they would not be able to see where their food should come from. Without food security, migrants' life would be greatly endangered.

Suffering from diseases. In the process of migration, health would be at high risk with the poor sanitation condition, imbalanced diet, accidental events, etc.; especially, the elderly are more susceptible to diseases. Far away from their former residential environment, some might suffer from physical and psychological disturbances caused under high pressure, which is mainly caused by nostalgia, or not being able to adapt to new living conditions and production methods.

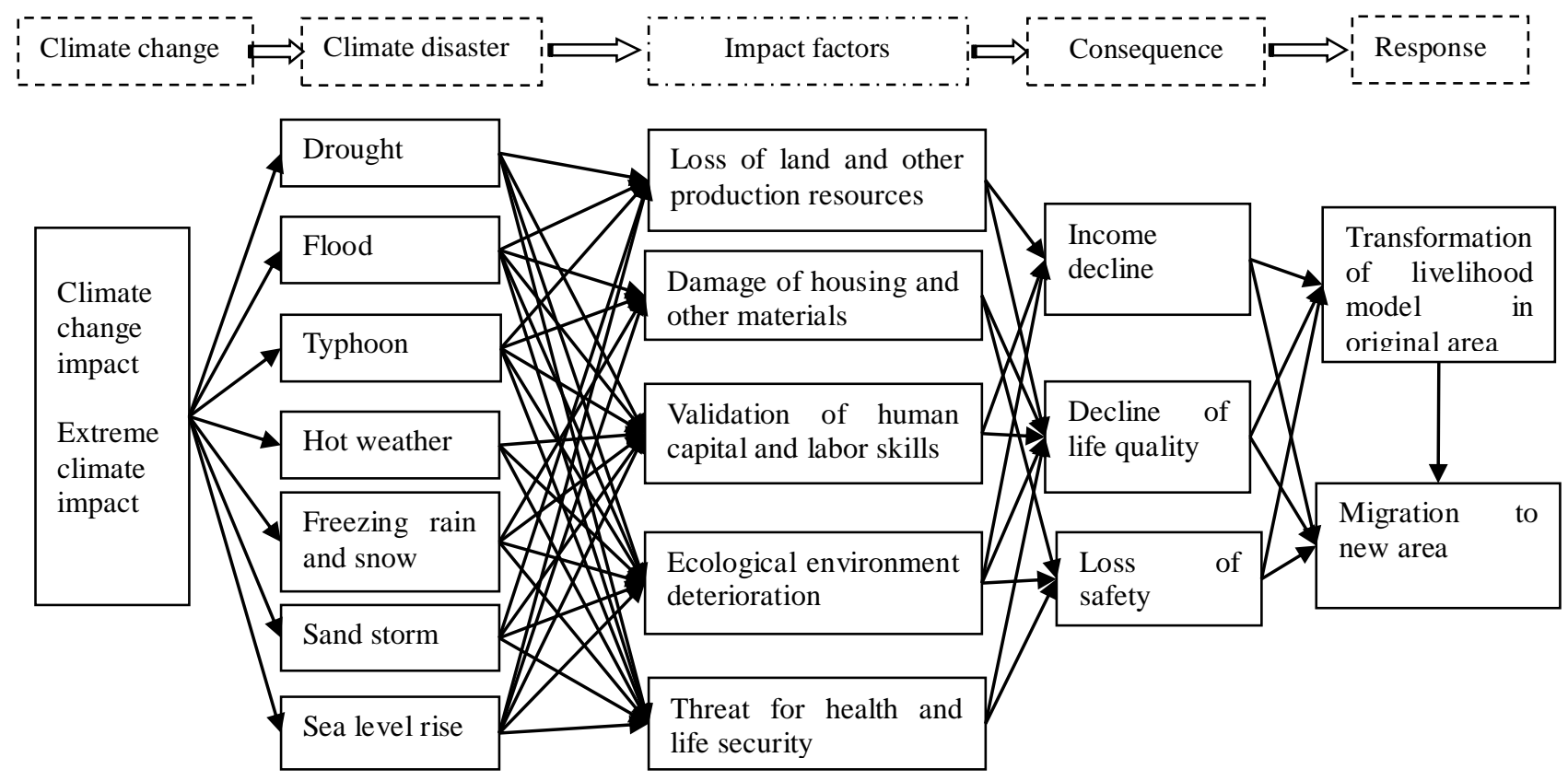

Fig 1. Conduction Mechanism Diagram of Climate Change Affecting Population Migration

\section{The mechanism of influence of human capital on climate migrants' livelihood}

In 1990, Schultz, in his report Investment in Human Capital released in the annual meeting of American Economic Association, pointed out that, economic growth should depend not only on workforce investment, but more importantly on the improvement of human abilities. According to Schultz, human capital is developed through investment on human resources, embodied as physical 
capacity, intelligence and techniques; it is another form of capital, with its tangible form being human resources. The mechanism of influence of human capital on climate migrants' livelihood is shown as figure 2 .

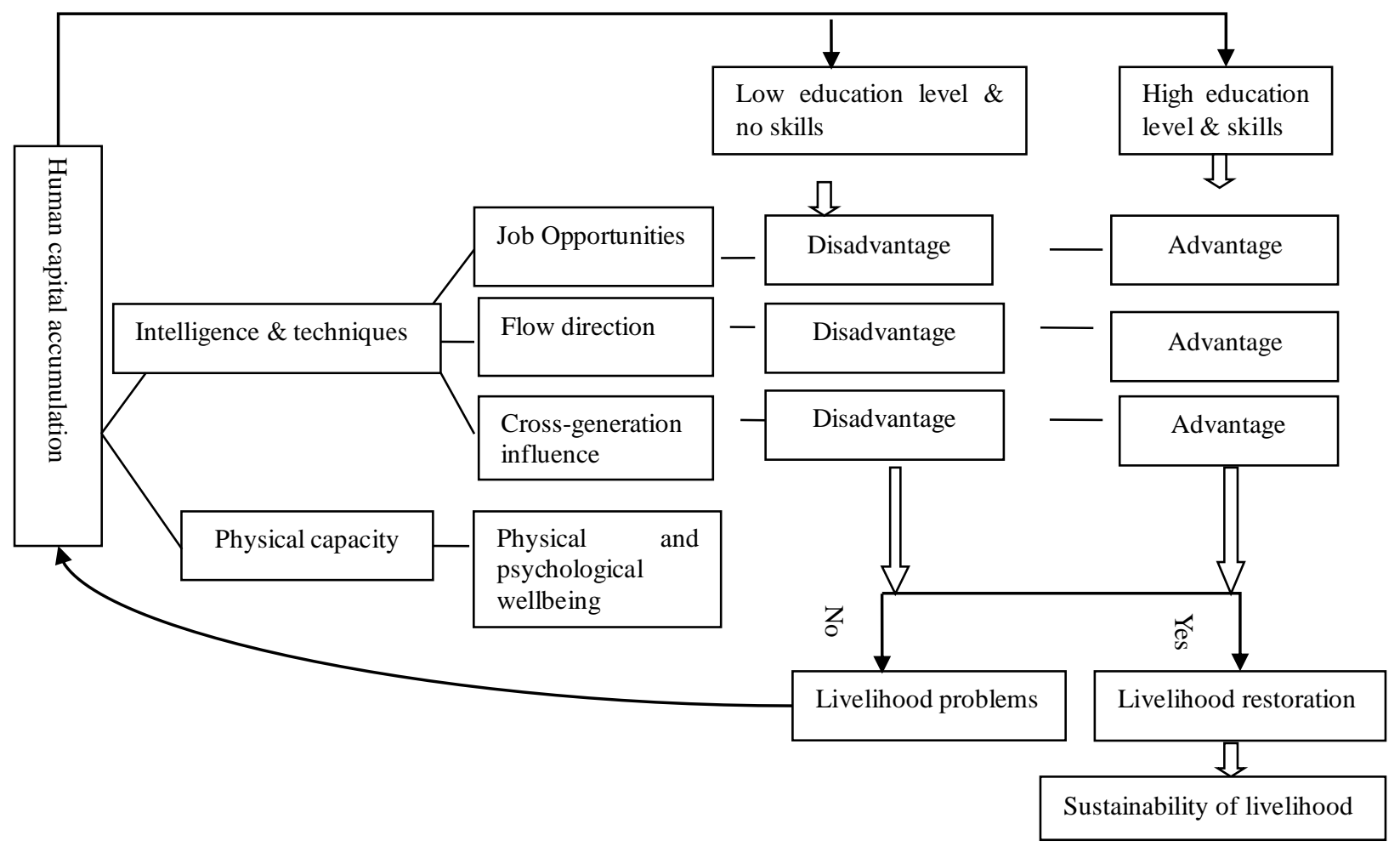

Fig. 2 Mechanism of influence of human capital on climate migrants' livelihood

Intelligence and techniques. From the perspectives of intelligence and techniques, human capital could be measured respectively by education levels and professional techniques acquired. Difference in education levels and techniques acquired determines the difference in livelihood. The education level, to some extent, could reflect the migrants' ability to understand and retain information. For instance, employers from many companies would set a limit on the education background of the applicants, and thus would exclude those who have received a low level of education. People who have acquired different professional techniques would choose different occupations, and those who have no working techniques might even have no choice to make. Therefore, those with a high education level and adequate professional techniques would stand a better chance of getting a job both stable and well paid, while those with a relatively low education level and inadequate professional techniques would only have few work opportunities, which hence explains the difference in income of different migrant groups.

The educational level and professional techniques would also have influence on the mobility of climate migrants, both horizontally and vertically. Migrants with a high education level and adequate professional techniques would be able to find jobs with steady income for their intelligence and skills, and thus have horizontal mobility; meanwhile they could also transfer from the primary industry to the secondary and tertiary industry, thus having the vertical mobility. Migrants with a relatively low education level and inadequate professional techniques would find that their lack of adequate education and techniques would be to their disadvantage in terms of mobility.

Educational levels and techniques of climate migrants would also exert influence on cross-generation human capital. Those with a high education level and adequate professional techniques, apart from having higher possibilities of finding stable and well-paid jobs, are capable of providing both material resources and moral support to the human capital accumulation of their next generation (the migrants themselves have also benefited from human capital), and they, with their own knowledge and techniques, could also help and coach their next generation for their education/occupation. The sustainability of cross-generation livelihood could be achieved through 
accumulation of cross-generation human capital.

Physical and mental health. Human capital of climate migrants could be measured by their state of health from the perspective of physical health status. Health is essential to one's life and career, and the effectiveness of human capital could only be maximized with good health. Migrants with a relatively low education level, inadequate professional techniques but good health would still be able to make a living through informal employment, such as doing part-time jobs or itinerant trading. Informal employment poses only minimum requirements on educational background and professional techniques, and is of various kinds; though it doesn't provide high salaries and stability, it's a fast way for migrants with low education levels and inadequate professional techniques as well as of old age to make money in the short-term.

\section{Reconstruction of human capital in climate migrants' livelihood restoration}

Human capital has significant and profound influence on the restoration of climate migrants' livelihood. In this regard, to facilitate efficient and effective restoration and development of climate migrants' livelihood, reconfiguration of their human capital could be carried out from the five aspects as follows.

Improvement in school education. Development of intelligence in large part depends on education, for which schools are the most important places. Sustainability of livelihood concerns both the sustainability of intra-generational livelihood and that of cross-generation. The formally organized school education is an important pathway to human capital accumulation, and would be helpful in their later career choice and job seeking. Firstly, implementation of the nine-year compulsory education should be strictly fulfilled with more capital investment in education so as to cultivate the basic learning abilities of the children of climate migrants; it's notable that the school and teachers should show no bias to children of climate migrants. Secondly, awareness of the importance of secondary vocational education should be improved in migrant groups, and the government should provide assistance for children of climate migrants who have graduated from middle school so that they could have the chance of receiving vocational education. Thirdly, the government and school could set up scholarship funds for migrant students so as to alleviated economic difficulties of migrant families. And in the secondary and advanced education, tuition expense abatement should be committed for migrant students so as to encourage them to finish their study. Education enhancement for the next generation of climate migrants would contribute to the sustainability of cross-generational livelihood.

Enhanced vocational training. Training is an important way for climate migrants to acquire necessary knowledge and techniques, which are a significant part of the human capital for sustainable livelihood as well as an effective way of reconfiguring human capital of migrants in the short-term. There are by far mainly five kinds of vocational training for climate migrants: the first one is vocational courses and training that migrants could decide whether they would participate in in accordance to their own needs; the second one is pre-employment training offered by employers; the third one is various vocational training offered by governments; the fourth one is order-driven vocational training offered by governments and employers with collaboration. The fifth one is a combination of training other than those mentioned above. For various training projects carried out by governments, they should make sure that features of these training projects are in line with those of migrant groups, and make sure the training projects all have taken in consideration the actual needs of the market. Different training methods should be taken for different people and different needs. Certificates should be granted to those who have passed examinations of the training projects, and trainees getting excellent results in training should be rewarded and put on the priority list for employment. Internships should be provided for migrant trainees so that they could get employed as early as possible.

Learning by working. The so-called learning by working means that migrants should learn to accumulate production techniques and experiences during their working practices, tapping their potentials by working so as to improve their skill level. It is also an effective way for climate migrants to acquire knowledge, improve working skills, and accumulate their human capital. 
To play full effectiveness of learning by doing on human capital accumulation for climate migration, the government should provide more internship opportunity for climate migrants, give technical guidance and demonstration, establish resettlement entrepreneurial demonstration park and internship base, develop various agricultural and non-agricultural demonstration projects, then make the climate migrants to quickly master the techniques of production and market experience in the internship procedure.

Enlarged investment in healthcare. Physical health is essential to human capital, and thus infrastructures, including public fitness facilities, bulletin boards for health and hygiene, etc., in migrant resettlement communities should be improved. Community workers should disseminate information and knowledge within the community about sound child rearing, balanced diet, endemic disease prevention, healthcare, mental hygiene, self-adjustment of mental state, interpersonal relationship harmonization, psychological disorder prevention, etc., and help organize mass sports activities. Efforts could be taken in collaborating with social forces and medical institutions to provide free or low-cost physical examination services on a regular basis, especially examinations against common illnesses that the elderly are prone to. Community workers take an active part in communication with migrant groups, offer help to people in need, and help them relieve mental pressures.

For the elderly climate migrants, attention should be paid to making sure that they have access to pension and medical insurance as local citizens, and to providing them with necessary help so that they could spend their years in comfort. And for middle-aged migrants with low education attainment and heavy burden of children's education, attention should be paid to making sure they are part of the social security system for urban and rural residents, and have access to minimum living allowances. The government should ensure that everyone who is entitled to subsistence allowances receives them, and more migrants in difficulty should be incorporated into the social security system for urban and rural residents. The social security system concerning healthcare, endowment insurance, social assistance, etc. should be strengthened and improved, so that climate migrants could all enjoy their rights to housing as well as medical and old-age care, while having fewer difficulties to worry about.

\section{References}

[1] Theodore W.Schultz.Investment in human Capital, London: Collier Macmillan, 1971.

[2]T.W. Schultz: 1961, Investment in Human Capital. The American Economic Review, Vol:51, No:15, 1035-1039.

[3]Harris, J. and M. Tadaro: 1970. Migration, Unemployment and Development: A Two-Sector Analyis. American Economic Review 60: 126-142.

[4]Cernea, Michael M., 1988. "Involuntary Resettlement and Development: Some Project have Adverse Social Effects Can These be Prevent” Finance and Development, Vol33(3), pp44-46.

[5]Becker, G.S. Human Capital: A Theoretical and Empirical Analysis, with Special Reference to Education. Chicago: The University of Chicago Press. 1964

[6]Stark, O. The Migration of Labor. Oxford: Basil Blackwell, 1991.

[7]Amartya Sen, Development as Freedom, Publisher: Knopf Group, 2000

[8] Chen Zhijun \& Cao Zhijie. The Concept and Types of Climate Immigrants Analysis [J]. China Population-Resources and Environment, 2012,22(6):166.(in Chinese)

[9] Yang Tao \& Yang Jianshe. A Study on Sustainable Livelihoods of Rural Involuntary Resettlement. Journal of Chongqing Three Gorges University, 2009,4(25):35. (in Chinese) 